AperTO - Archivio Istituzionale Open Access dell'Università di Torino

\title{
Prospective translational study investigating molecular PrEdictors of resistance to first-line Pazopanlb in Metastatic reNal CEll Carcinoma (PIPELINE Study)
}

\section{This is a pre print version of the following article:}

Original Citation:

Availability:

This version is available http://hdl.handle.net/2318/1770062

since 2021-01-29T16:25:56Z

Published version:

DOI:10.1097/COC.0000000000000719

Terms of use:

Open Access

Anyone can freely access the full text of works made available as "Open Access". Works made available under a Creative Commons license can be used according to the terms and conditions of said license. Use of all other works requires consent of the right holder (author or publisher) if not exempted from copyright protection by the applicable law. 
Prospective translational study Investigating molecular PrEdictors of resistance to first-Line pazopanIb in metastatic reNal cEll carcinoma (PIPELINE Study)

\author{
Pierangela Sepe ${ }^{1}$, Alessia Mennitto ${ }^{1}$, Elena Verzoni ${ }^{1}$, Melanie Claps $^{1}$, Alessandra Raimondi ${ }^{1}$, Antonia \\ Martinetti ${ }^{1}$, Roberta Mennitto ${ }^{1}$, Paolo Grassi ${ }^{1}$, Valentina Guadalupi ${ }^{1}$, Massimo Di Maio ${ }^{2}$, Giuseppe \\ Procopio $^{1}$
}

1. Department of Medical Oncology Unit, Fondazione IRCCS Istituto Nazionale dei Tumori di Milano, Milan, Italy.

2. Department of Oncology, University of Turin, Ordine Mauriziano Hospital, Turin, ITALY

3. Department of Medical Oncology \& Hematology, University of Milan, via Festa del Perdono 7, 20122 Milan, Italy.

Corresponding Author: Pierangela Sepe, pierangela.sepe@istitutotumori.mi.it

\begin{abstract}
Background: tyrosine kinase inhibitors have significantly improved the outcomes in metastatic renal cell carcinoma (mRCC) patients (pts). Despite initial clinical benefit, resistance to antiangiogenic therapies develops through the activation of alternative angiogenic pathways. Plasma levels of circulating angiogenic factors (CAFs) were mesured in pts with mRCC treated with pazopanib to identify predictive biomarkers of resistance. Methods: PTS with mRCC treated with pazopanib in first-line at Istituto Nazionale Tumori of Milan between July 2015 and February 2017 were enrolled in this prospective trial. Levels of 7 CAFs of interest including interleukin-6 (IL-6), interleukin-8 (IL-8), stromal cell-derived factor 1 (SDF-1), vascular endothelial growth factor (VEGF), hepatocyte growth factor (HGF), Osteopontin and E-selectin, quantified by immunometric technology, were obtained before treatment and every 4 weeks until disease progression (PD) defined by RECIST Criteria 1.1. Wilcoxon test for paired samples was used to compare CAFs levels at baseline (B) and PD. Results: Overall, 25 pts were included in the final dataset. Median follow up was 31.9 months. As best response, 12 patients presented partial response (48\%), while 9 presented a stable disease and 4 a PD. At time of analysis, 6 patients (24\%) were still on treatment, $15(60 \%)$ discontinued treatment for PD and $4(16 \%)$ stopped pazopanib due to toxicity. Median progression-free survival was 14.8 months. Paired plasma samples from the 15 pts with PD were analyzed. Overall, median plasma levels of SDF-1 and VEGF resulted significantly higher at PD compared to B [SDF-1: B 574,67 pg/mL (range 200,8-2.018,39) vs PD 1328,03 pg/mL (range 472,55-2.126,96) p=0,011; VEGF-A: B 45,10 pg/mL (range 6,16-256,14) vs PD 62,4 pg/mL (range
\end{abstract}


39,42-186,74) $\mathrm{p}=0,011]$. Conversely, median levels of E-selectin were significantly lower at PD compared to B [B 23.882,51 pg/mL (range 11.016,44-56.948,61) vs PD 20.588,30 pg/mL (range 10.991,75-38.415,71) $\mathrm{p}=0,017]$. None of the remaining CAFs evaluated showed a significant variation between $\mathrm{B}$ and PD. Additionally, patients with lower baseline levels of HGF showed longer PFS and OS, while lower baseline levels of IL-8 showed longer OS compared to patients with the higher corresponding CAF. Conclusions: Low baseline levels of IL-6, IL-8, HGF and Osteopontin were associated to tumor response to pazopanib while higher plasma levels of SDF-1 and VEGF-A were associated with PD during first-line pazopanib than at B.Thus, levels of selected CAFs during treatment with pazopanib may represent potential candidates to predict resistance and PD to therapy. These findings warrant further investigation in larger trials.

Key words: renal cell carcinoma, circulating angiogenic factors, TKI, pazopanib,targeted therapies, circulating biomarkers

\section{Introduction}

Renal cell carcinoma (RCC) is a highly vascular tumor, arising from epithelial elements within the proximal tubules of nephrons. Overexpression of vascular endothelial growth factor (VEGF), often due to the alteration of the von Hippel-Lindau (VHL) gene, stimulating tumor growth and angiogenesis, plays an important role in RCC pathogenesis (1). Several agents that target the VEGF pathway in different ways, i.e. blocking the pathways that regulate hypoxia-inducible factors (HIF $\alpha$ ) levels, directly inhibiting the function of VEGF, or interrupting the signaling cascade downstream the VEGF receptor via tyrosine kinase inhibitors (TKIs), are approved for the treatment of RCC (2) (3) (4). In the last decades, the anti-vascular TKIs significantly improved outcomes in metastatic renal cell carcinoma (mRCC) patients (3) (4). Among TKIs, pazopanib is a potent multitarget inhibitor of VEGF receptors (VEGFR) 1, 2, and 3, PDGF receptors $\alpha$ and $\beta$ and stem cell factor receptor (c-Kit) (5), with a higher binding affinity in vitro for VEGFR-2 compared to sunitinib (6). Pazopanib showed to improve progression-free survival (PFS) and overall survival (OS) in mRCC with a comparable efficacy to sunitinib (7) (8) (9) (10). However, about $20 \%$ of patients treated with TKIs derive no benefit from the treatment due to primary resistance, while the remaining proportion of patients could experience disease progression due to secondary resistance after an initial response to the treatment, after a median time of one year (11) (12).

Thus, understanding the mechanisms underlying primary and secondary resistance to TKIs is fundamental to identify predictive biomarkers to guide the future treatment choice and to develop new targeted agents with the aim to improve patients'clinical outcomes. 
Several studies reported that the activation of alternative angiogenic pathways in both tumor cells and stroma could contribute to develop resistance to treatment (13) (14). Despite a successful inhibition, in fact, the activation of alternative ligands/receptors that sustain the signaling of key downstream pathways could lead to escape the pharmacological inhibition of the VEGF/VEGFRaxis (15). Different mechanisms involved in resistance are reported in literature, such as MET proto-oncogene receptor tyrosine kinase (MET)/hepatocyte growth factor (HGF) pathway activation and IL-8 (10) (16). Preclinical studies detected higher HGF levels in the stromal compartment of resistant tumor and an overexpression of its receptor c-Met on the endothelial tumor cell surface (17). Concerning IL-8, it is a chemokine member of the CXC family implicated in tumor growth and angiogenesis. An increased serum level and tissue overexpression of IL-8 was in fact documented in primary resistant mRCC models (18) (19) (20). Changes in plasma cytokines and circulating angiogenic factors (CAFs), including IL-8, IL-6, SDF1, HGF, FGF, VEGF, and Osteopontin may therefore provide evidence for the biologic activity of pazopanib and could retain the potential to be used as serum biomarkers able to predict drug response and/or resistance. The use of CAFs as potential surrogate biomarkers has been examined in $\mathrm{mRCC}$, but unfortunately no prospective trials are ongoing to evaluate them (21).

PIPELINE trial, was designed to assess prospectively the plasma levels of CAFs in patients with mRCC treated with pazopanib as first line therapy, .

Here, we report the results from translational analyses on change in circulating biomarkers (IL-6, SDF1, IL-8, Osteopontin, VEGF, HGF and FGF) between blood samples taken at baseline (before starting treatment) and at the time of PD as per RECIST 1.1 in order to better understand changes as resistance develops. At time of manuscript writing, analysis on tissue samples were ongoing.

\section{Material and Methods}

\subsection{Study design}

This prospective single-centre translational research study, the PIPELINE study, conducted at Fondazione IRCCS Istituto Nazionale dei Tumori of Milan Italy, was designed to evaluate biomarkers associated with drug resistance to TKI in a cohort of $\mathrm{mRCC}$ patients suitable to receive pazopanib as first line treatment. Pazopanib was given $800 \mathrm{mg}$ orally daily (cycles of 28 days) until disease progression (PD) or unacceptable toxicity.

Our study included the collection of blood and tumor tissue samples. Blood samples were obtained at baseline, during treatment and at time of PD. Tumor tissue samples were obtained for all patients by collecting pre-existing archival tumor specimen if available, or by a fresh biopsy before treatment and, optionally, upon progression if safe and technically feasible. 
Tumor restaging was performed every 12 weeks +/- 7 days, as per clinical practice. Patients were monitored until PD, withdrawal from the study, intolerable toxicity or study completion. All the patients provided written informed consent before undergoing any trial procedures. All the procedures set out in this study were consistent to Good Clinical Practice Guidelines and Declaration of Helsinki.

\subsection{Patients}

Eligible patients were adults $\geq 18$ years old with histological confirmed diagnosis of RCC displaying a clear cell component and/or sarcomatoid features not previously treated with any systemic treatment, including agents in the adjuvant setting. Patients should have evidence of advanced or metastatic disease with measurable lesions according to the Response Evaluation Criteria in Solid Tumors (RECIST) version 1.1. Patients were required to have Eastern Cooperative Oncology Group (ECOG) performance status of 0 and 1, adequate bone marrow, liver, renal and pancreatic function. Mandatory was the availability of either an archival or newly collected formalin-fixed, paraffinembedded (FFPE) tumor tissue sample.

Patients were excluded if they had diagnosis of concomitant cardiac disorders including uncontrolled hypertension, clinically significant gastrointestinal abnormalities that could increase the risk for gastrointestinal bleeding, history of cerebrovascular accident including transitory ischemic attack (TIA), pulmonary embolism or untreated deep venous thrombosis (DVT) within the past 6 months, major surgery or trauma within 28 days prior to first dose of pazopanib and/or presence of any non-healing wound, fracture, or ulcer, known endobronchial lesions and/or lesions infiltrating major pulmonary vessels that increase the risk of pulmonary hemorrhage.

\subsection{Procedures}

\section{Blood collection}

Blood samples were collected for all eligible patients at baseline, every 4 weeks during pazopanib treatment and at the time of PD defined by RECIST 1.1. Whole blood $(10 \mathrm{ml})$ was collected in K2EDTA Vacutainer tubes and plasma was separated by centrifugation $3000 \mathrm{rpm} 4^{\circ} \mathrm{C}$ for $15 \mathrm{~min}$. Plasma levels of 7 circulating angiogenic factors (CAFs) of interest, including IL-6, IL-8, VEGF-A, HGF, Osteopontin and E-selectin, were quantified by Luminex ${ }^{\circledR}$ technology, (Luminex Human Magnetic Assay 6-Plex LXSAHM-06 HGF, IL-6, IL-8/CXCL8, Osteopontin, E-Selectin, VEGF-A) as per standard protocol. Luminex ${ }^{\circledR}$ technology Assays utilize color-coded superparamagnetic 
beads coated with analyte-specific antibodies. Beads recognizing different target analytes are mixed together and incubated with the sample. Captured analytes were subsequently detected using a cocktail of biotinylated detection antibodies and a streptavidin-phycoerythrin conjugate. Conversely, plasma level of SDF-1 was determined using the quantitative sandwich enzyme immunoassays (ELISA) assay kits, Quantikine ${ }^{\circledR}$ by R\&D Systems ${ }^{\circledR}$ (Human CXCL12/SDF-1 alpha Quantikine) as per standard protocol.

Furthermore, at baseline and every 12 weeks during pazopanib treatment and at the time of PD whole blood $(30 \mathrm{ml})$ was collected for peripheral blood mononuclear cells (PBMC) separation and storage in liquid nitrogen for subsequent analyses, together with corresponding plasma samples.

All patients provided written informed consent before undergoing any trial procedures.

\subsection{Objectives}

Primary objectives of the study were: to identify molecular predictive biomarkers of resistance to first line treatment with pazopanib in $\mathrm{mRCC}$ by using next-generation sequencing (NGS) methods; Overall Response Rate (ORR) defined as the rate of complete response (CR) plus partial response (PR) as per RECIST 1.1 to pazopanib.

Secondary objectives were: to collect blood samples from mRCC patients treated with pazopanib in first line to identify circulating predictive biomarkers of resistance/response to TKI; to compare change in promising circulating biomarkers (including SDF1, IL-6, IL-8, Osteopontin, VEGF, HGF and E-selectin) between blood samples taken at baseline and at the time of PD as per RECIST 1.1 in order to better understand changes in the tumor and in the levels of CAFs when resistance develops; to collect prospective and retrospective demographic, clinical and pathological data to correlate change in biomarkers to clinical outcomes; to perform subgroup analyses comparing the tissue and blood biomarkers identified in patients who developed secondary resistance with those biomarkers identified in patients who have primary resistance; to assess the modulating effect of pazopanib treatment on immune cell profile (in terms of frequency and function of different lymphocytes and myeloid cell populations) in peripheral blood and tumor biopsies if available. Tumor response was performed according to the Response Evaluation Criteria in Solid Tumors (RECIST) version 1.1. At time of manuscript writing, analysis on tissue samples and immune cells profile were ongoing.

\subsection{Statistical analysis}


For within-patient comparison of candidate genes/biomarkers of tissue samples taken at baseline ad upon PD, we used a Mc Nemar test. To compare previously defined promising circulating predictive biomarkers for pazopanib treatment between blood samples taken at baseline and at the time of PD we used a Mc Nemar test for dichotomous outcome and Wilcoxon test for continuous data. Tables of frequencies and percentages were calculated for discrete variables. Circulating variables were analyzed by statistical descriptive procedures. Changes in CAFs were observed in terms of different expression levels in blood Patients were dichotomize into "low" and "high" cytokine and circulating angiogenic factors (CAFs) subgroups by cutoff points defined by the respective median CAF value as consistent with literature (21). The Kaplan-Meier method was used for survival analyses to estimate PFS and OS. We used the Log-Rank test to compare PFS and OS between the low and the high CAF subgroups. Correlation with ORR were performed by using Fisher exact test, statistical significance threshold was set to a canonical two-tailed 0.05 value. Given the exploratory nature of the analysis, no formal correction for multiple testing was applied.

\section{Results}

Patients

A number of 27 patients eligible for a first line treatment with pazopanib $800 \mathrm{mg}$ daily for untreated mRCC were prospectively enrolled at Istituto Nazionale Tumori of Milan between July 2015 and February 2017. All patients, except for one, were caucasian and all had a confirmed clear cells histology. Among all patients enrolled, 25 patients were included in the final data set since 2 patients resulted screening failure for consent withdrawal. Median age was 65 years old (range 54 73). At the data cutoff date for PFS of May 5th 2019, 6 patients continued to receive the study treatment (Figure 1). The most common reason for discontinuing treatment was radiological PD. Median follow-up was 31.9 months. A pre-existing archival tumor specimen was available for all patients receiving study treatment. Upon progression, an optional biopsy was obtained for 3 patients. Baseline characteristics are summarized in Table 1.

\section{Tumor response}

Among 25 patients receiving pazopanib, partial response was observed in 12 patients, for a response rate of $48 \%$, while 9 presented a stable disease and 4 a PD as best response. At time of analysis, 6 patients $(24 \%)$ were still on treatment, 15 patients $(60 \%)$ experienced a radiological PD and 4 (16\%) stopped pazopanib due to toxicity. Median progression-free survival was 14.8 months (Suppl. Fig. 1a). Median overall survival (OS) was not reached (Suppl. Fig. 1b). 


\section{Blood collections}

Blood samples were processed for all patients for the determination of changes in candidate biomarkers that may potentially correlate with first-line pazopanib therapy resistance.

Patients were dichotomized into two groups according to the baseline level of CAFs: "low" ( $\leq$ cutoff value) and "high" ( $>$ cutoff value) subgroups by a cutoff point chosen considering the baseline median value of each factors, as reported in literature (21). Correlation with ORR in high versus low subgroups were performed and are showed in Table 2 - 3. Overall, low baseline levels of IL-6, IL-8, HGF and Osteopontin showed to be significantly associated to objective response to treatment with pazopanib. However, we identified no significant association with ORR for baseline levels of SDF1, VEGF and E-selectin.

Among the 15 patients experiencing a radiological PD, changes in CAF's plasma level between blood samples taken at baseline (B) and at the time of PD were compared. Overall, median plasma levels of SDF-1 and VEGF-A resulted significantly higher at PD compared to baseline. Conversely, E-selectin was significantly lower at PD compared to basal (Figure 2). None of the remaining CAFs evaluated showed a significant modification between baseline and PD. Change in CAFs level are summarized in Table 4 and illustrated in Figure 3.

Additionally, patients with lower IL-8 levels at baseline showed a significantly longer OS (p 0.04) compared to patients with higher levels of IL-8 at baseline (Figure 4). Moreover, lower HGF levels at baseline showed longer PFS (p 0,0021) and OS ( $p$ 0.0226) compared to basal higher levels (Figure 5). However, we identified no significant differences in PFS and OS for other CAFs (Suppl. Fig. 2-3).

\section{Discussion}

The purpose of our study was to explore potential biomarkers of resistance or response to a first line treatment with pazopanib in mRCC patients through the assessment of plasma levels of a set of CAFs by using a commercially available kit that showed to be cost effective and easily reproducible. The assessed CAFs were IL-6, IL-8, SDF-1, VEGF, HGF, Osteopontin and Eselectin. They all are components of the angiogenesis system and molecular factors modulated by the activation of alternative anti-angiogenic pathways (14) (21) (22) (23) (24). There is strong evidence, in fact, that angiogenesis plays an important role in RCC pathogenesis and it is reported that the activation of alternative anti-angiogenic pathways could contribute in determining resistance to anti-angiogenic treatment with TKIs (13). As reported by Pal et al, RCC biology 
changes during therapy and between treatment lines, with a multitude of genomic alterations arising as a consequence of selective pressure from therapy (25). For example, VHL tumor suppressor gene is frequently mutated in RCC and its alterations are reported to increase during disease course. These findings suggest that angiogenesis remain a key mechanism in determining resistance to TKI. In addition, recent reports suggested that $V H L$ and p53 act in synergy in the regulation of cell proliferation and apoptosis. Furthermore, the regulatory role of $V H L$ is dependent on the activation p53, providing a plausible explanation for VEGF directed therapy (26).

Current blood biomarkers may provide prognostic information but they are not known to be predictive. Serum levels of immunomodulatory factors including, IL-6, IL-8, HGF and Osteopontin were reported to be associated with prognosis in different studies (21) (27) (28) (29). Tran et al. showed that higher baseline IL-8, HGF and Osteopontin levels were associated with a shorter PFS in patients treated with pazopanib in first line. On the other hand, in the placebo group, high concentrations of IL-6 and IL-8 were all associated with shorter PFS (21). We also assessed whether CAFs added prognostic information and, in fact, consistent with literature, our results confirmed that patients with lower baseline levels of HGF showed longer PFS and OS, while lower baseline levels of IL-8 showed longer OS compared to patients with the higher corresponding CAF.

Thus, CAF's profile could provide prognostic information and identify potential predictive biomarkers of benefit from treatment with anti-angiogenic agents.

In our analysis, we defined two distinct and equally sized groups on the basis of basal value of CAFs that were dichotomized in "high" versus "low" considering the baseline median value of each factor. Among all CAFs, only IL-6, IL-8, HGF and Osteopontin showed to be significantly associated to objective response; i.e. patients with "low" levels of the marker had a statistically significant higher proportion of objective response to treatment. Thus, pre-treatment plasma level of these markers could be useful to predict response to pazopanib.

As reported in literature, plasma levels of proangiogenic molecules, SDF-1 and VEGF, seem to provide prognostic information. In particular, basal high levels of VEGF have been associated with worse outcome, to confirm the fact that VEGF expression levels are involved in the development and progression of renal parenchymal tumors (30) (31) (32). Moreover, both VEGF and SDF-1 were found to increase on sunitinib and correlate with outcome, reflecting severe sunitinib-induced hypoxia in the tumor (33) (34). It is now clear that antiangiogenic treatment efficiency depends on the hypoxic status of the tumor and the degree of hypoxia induced by antiangiogenic drugs, therefore this mechanism could explain the occurrence of resistance to therapy (35) (36). 
In addition, SDF-1, by binding its receptor $\mathrm{CXCR} 4$, promotes tumor proliferation, inhibits apoptosis and enhance tumor associated angiogenesis (37) (38) working synergistically with VEGF. Our analysis showed that plasma levels of SDF-1 and VEGF resulted significantly higher at progression compared to baseline, similarly to what observed in sunitinib-treated patients (39) (40). These results suggest that even during pazopanib therapy these circulating factors may participate in mechanisms of resistance and may be a potential therapeutic target.

Conversely, we found that E-selectin was significantly lower at PD compared to baseline. Analysis of the literature highlights that E-selectin is involved in adhesion between RCC and endothelial cells and inflammatory cytokine production. Moreover, an excessive production of circulating Eselectin has an inhibitory effect on developing metastasis (41) (21). Thus, plasma level of SDF-1, VEGF and E-selectin could be used not only to provide prognostic information but also to potentially predict outcomes in patients treated with pazopanib.

To date, immunotherapy is significantly changing the frontline treatment landscape for patients with mRCC, indeed the combination of ipilimumab and nivolumab has been approved in treatment-naïve patients with intermediate- or poor-risk disease (42) (43) (44) (45). Notwithstanding this, some patients might still benefit from monotherapy with TKI as first line treatment. As recently showed by the Checkmate 214 trial, anti-angiogenic drugs remain of interest for patients with favorable risk mRCC. Thus, the introduction of biomarkers of response or resistance in the clinical practice has the potential to considerably improve the attempts to individualize patient prognostication and treatment strategies. The set of CAFs that we used in our analysis, for example, may be of value as biomarkers of the angiogenic processes and the pharmacological and clinical activity of anti VEGFdriven therapy in RCC.

Strengths of our study are the prospectively collected data and the fact that we analyzed samples of patients that were naïve to pazopanib treatment, allowing the assessment of correlation between baseline biomarkers, clinical outcome, and primary tumor response. On the other hand, the limitation of our analysis is the small sample size that did not allowed to perform a multivariate analysis and hampers the clinical and statistical significance of the results obtained; moreover, in the current series, tissue-based genomic profiling data and immune-cells profile results were not available yet.

Therefore, further research and larger studies are warranted in order to confirm the predictive value of the biomarkers explored.

\section{Conclusion}

Our analysis showed that low baseline levels of IL-6, IL-8, HGF and Osteopontin showed to be significantly associated to tumor response to pazopanib. Moreover, higher plasma levels of SDF-1 
and VEGF-A were significantly associated with disease progression during first-line pazopanib. These results suggest the activation of an alternative angiogenic pathway as a mechanism of resistance to pazopanib. Thus, monitoring CAFs levels during treatment could have the potential to predict resistance and individualize treatment strategies. These findings warrant further investigation in larger clinical trials.

\section{Opere citate}

1. Latif F, Tory K, Gnarra J, et al. Identification of the von Hippel-Lindau disease tumor suppressor gene. Science. 1993 May 28;260(5112):1317-20.

2. Bukowski RM. Cytokine therapy for metastatic renal cell carcinoma. Semin Urol Oncol. 2001;19(2):148154.

3. Motzer RJ, Russo P. Systemic therapy for renal cell carcinoma. J Urol. 2000;163(2):408-417.

4. Rini BI, Small EJ. Biology and clinical development of vascular endothelial growth factor-targeted therapy in renal cell carci noma. J Clin Oncol. 2005;23(5):1028-1043.

5. Sonpavde G, Hutson TE, Sternberg CN. Pazopanib, a potent orally administered small-molecule multitargeted tyrosine kinase inhibitor for renal cell carcinoma.. Expert Opin Investig Drugs. 2008 Feb;17(2):253-61. Review.

6. Kumar R, Crouthamel MC, Rominger DH, et al. Myelosuppression and kinase selectivity of multikinase angiogenesis inhibitors. Br J Cancer. 2009 Nov 17;101(10):1717-23.

7. Sternberg CN, Davis ID, Mardiak J et al. Pazopanib in locally advanced or metastatic renal cell carcinoma: results of a randomized phase III trial. J Clin Oncol. 2010 Feb 20;28(6):1061-8.

8. Motzer RJ, Hutson TE, Cella D, et al Pazopanib versus sunitinib in metastatic renal-cell carcinoma. N Engl J Med. 2013 Aug 22;369(8):722-31.

9. Prospective Observational Study of Pazopanib in Patients with Advanced Renal Cell Carcinoma (PRINCIPAL Study). Oncologist. 2019 Apr;24(4):491-497. Schmidinger M, Bamias A, Procopio G et al.

10. Real-world Effectiveness and Safety of Pazopanib in Patients With Intermediate Prognostic Risk Advanced Renal Cell Carcinoma.Clin Genitourin Cancer. 2019 Jun. Procopio G, Bamias A, Schmidinger M et al.

11. Ravaud A, Gross-Goupil M. Overcoming resistance to tyrosine kinase inhibitors in renal cell carcinoma Cancer Treat Rev. 2012 Feb 11. 
12. Hutson TE Targeted therapies for the treatment of metastatic renal cell carcinoma: clinical evidence. Oncologist. 2011;16 Suppl 2:14-22.

13. Hernandez-Yanez M, Heymach JV, Zurita AJ. Circulating biomarkers in advanced renal cell carcinoma: clinical applications. Curr Oncol Rep. 2012 Jun;14(3):221-9.

14. Bergers G, Hanahan D. Modes of resi stance to anti-angiogenic therapy. Nat Rev Cancer 2008 8(8):592603.

15. Shojaei F, Lee JH, Simmons BH et al HGF/c-Met acts as an alternative angiogenic pathway in sunitinibresistant tumors. Cancer Res. 2010 Dec 15;70(24):10090-100.

16. 1) Corso S, Giordano S. Cell-autonomous and non-cell-autonomous mechanisms of HGF/MET-driven resistance to targeted therapies: from basic research to a clinical perspective. Cancer Discov.

17. Zhang YW, SU Y, Volpert OV Hepatocyte growth factor/scatter factor mediates angiogenesis through positive VEGF and negative thrombospondin 1 regulation. Proc Natl Acad Sci U S A. 2003 Oct 28;100(22):12718-23.

18. Waugh DJ, Wilson C The interleukin-8 pathway in cancer. Clin Cancer Res. 2008 Nov 1;14(21):6735-41.

19. Mizukami Y, Jo WS, Duerr EM et al Induction of interleukin-8 preserves the angiogenic response in HIF1alpha-deficient colon cancer cells. Nat Med. 2005 Sep;11(9):992-7.

20. Huang $D$, Ding $Y$, Zhou $M$ et al Interleukin-8 mediates resistance to antiangiogenic agent sunitinib in renal cell carcinoma. Cancer Res. 2010 Feb 1;70(3):1063-71.

21. Tran HT, Liu Y, Zurita AJ et al Prognostic or predictive plasma cytokines and angiogenic factors for patients treated with pazopanib for metastatic renal-cell cancer: a retrospective analysis of phase 2 and phase 3 trials. Lancet Oncol. 2012 Jun 29.

22. Ferrara N, Gerber HP, Lecouter J. The biology of VEGF and its receptors. Nat Med. 2003 Jun;9(6):669-76.

23. Deprimo SE, Bello CL, Smeraglia J et al. Circulating protein biomarkers of pharmacodynamic activity of sunitinib in patients with metastatic renal cell carcinoma: modulation of VEGF and VEGF-related proteins. $J$ Transl Med. 2007 Jul 2;5:32.

24. A.J. Zurita, E. Jonasch, $\mathbf{X}$. Wang et al. A cytokine and angiogenic factor (CAF) analysis in plasma for selection of sorafenib therapy in patients with metastatic renal cell carcinoma. Ann Oncol, 23 (1) (2012), pp. 46-52.

25. Evolution of Circulating tumor DNA Profile from First-line to Subsequent Therapy in Metastatic Renal Cell Carcinoma. Eur Urol. 2017 Oct;72(4):557-564. doi: 10.1016/j.eururo.2017.03.046. Pal SK, Sonpavde G, Agarwal $\mathbf{N}$ et al.

26. Synergy between von Hippel-Lindau and P53 contributes to chemosensitivity of clear cell renal cell carcinoma. Mol Med Rep. 2016 Sep;14(3):2785-90. doi: 10.3892/mmr.2016.5561. Zhao Z, Chen C, Lin J et al. 
27. Negrier S, Perol D, Menetrier-Caux C, Escudier B, Pallardy M, Ravaud A, et al. Interleukin-6, interleukin10 , and vascular endothelial growth factor in metastatic renal cell carcinoma: prognostic value of interleukin-6--from the Groupe Francais d'Immunoththerapie. J Clin Oncol. 2004;22(12):2371-8.

28. Montero AJ, Diaz-Montero CM et al. Cytokines and angiogenic factors in patients with metastatic renal cell carcinoma treated with interferon-alpha: association of pretreatment serum levels with survival. Ann Oncol. 2009;20(10):1682-7.

29. Liu Y, Tran HT, Lin Y, Martin AM et al. Baseline (BL) IL-6, IL-8, and VEGF as Predictive and Prognostic Markers for Overall Survival (OS) in Metastatic Renal Cell Carcinoma (mRCC) Patients (pts) Treated in a Phase III Trial of Pazopanib (PAZO) Versus Placebo (PL). Eur J Cancer. 2011;47(suppl 1).

30. Harmon CS, DePrimo SE, Figlin RA et al. Circulating proteins as potential biomarkers of sunitinib and interferon-alpha efficacy in treatment-naive patients with metastatic renal cell carcinoma. Cancer Chemother Pharmacol 2014;73:151-61.

31. Expression level of vascular endothelial growth factor receptor-2 in radical nephrectomy specimens as a prognostic predictor in patients with metastatic renal cell carcinoma treated with sunitinib. Urol Oncol. 2013; 31:493-498. . Terakawa T, Miyake H, Kusuda Y et al.

32. DJ George, MD Michaelson, JE Rosenberg, et al. Phase II trial of sunitinib in bevacizumab-refractory metastatic renal cell carcinoma ( $m R C C)$ : Updated results and analysis of circulating biomarkers I Clin Oncol 25: 243s,2007 suppl abstr 5035.

33. Farace F, Gross-Goupil M, Tournay E et al. Levels of circulating CD45(dim)CD34(+)VEGFR2(+) progenitor cells correlate with outcome in metastatic renal cell carcinoma patients treated with tyrosine kinase inhibitors Br J Cancer. 2011 Mar 29;104(7):1144-50.

34. Kontovinis LF1, Papazisis KT, Touplikioti P, et al. Sunitinib treatment for patients with clear-cell metastatic renal cell carcinoma: clinical outcomes and plasma angiogenesis markers. BMC Cancer. 2009 Mar 12;9:82. doi: 10.1186/1471-2407-9-82.).

35. Regulation of the chemokine receptor CXCR4 by hypoxia. J Exp Med. 2003;198:1391-1402. doi: 10.1084/jem.20030267. Schioppa T, Uranchimeg B, Saccani A et al.

36. Molecular mechanisms and clinical applications of angiogenesis. Nature 2011;473:298-307. Carmeliet P, Jain RK.

37. Jin DK, Shido K, Kopp HG et al. Cytokine-mediated deployment of SDF-1 induces revascularization through recruitment of CXCR4+ hemangiocytes. Nat Med 12(5):557-567, 2006.

38. Liang Z, Brooks J, Willard M. CXCR4/CXCL12 axis promotes VEGF-mediated tumor angiogenesis through AKT signaling pathways. Biochem Biophys Res Commun 359(3):716-722, 2007).

39. John M. L. Ebos, Christina R. Lee, James G. Christensen et al. Multiple circulating proangiogenic factors induced by sunitinib malate are tumor-independent and correlate with antitumor efficacy. Proc Natl Acad Sci U S A. 2007 Oct 23;104(43):17069-74. . 
40. Mateo J, Heymach JV, Zurita AJ. Circulating biomarkers of response to sunitinib in gastroenteropancreatic neuroendocrine tumors: current data and clinical outlook. Mol Diagn Ther. 2012;16(3):151-161.

41. he intercellular cell adhesion molecule-1 (icam-1) in lung cancer: implications for disease progression and prognosis. Anticancer Res. 2014;34:4665-72. Kotteas EA, Boulas P, Gkiozos I et al.

42. Nivolumab plus ipilimumab versus sunitinib in first-line treatment for advanced renal cell carcinoma: extended follow-up of efficacy and safety results from a randomised, control. Lancet Oncol. 2019 Oct;20(10):1370-1385. Motzer RJ, Rini BI, McDermott DF et al.

43. Rini Bl, Plimack ER, Stus V et al. Pembrolizumab plus Axitinib versus Sunitinib for Advanced Renal-Cell Carcinoma. March 21, 2019. N Engl J Med 2019; 380:1116-1127.

44. Motzer RJ, Penkov K, Haanen J, et al. Avelumab plus Axitinib versus Sunitinib for Advanced Renal-Cell Carcinoma. March 21, 2019. N Engl J Med 2019; 380:1103-111.

45. 6. Rini BI, Powles $T$, Atkins $M B$, et al. Atezolizumab plus bevacizumab versus sunitinib in patients with previously untreated metastatic renal cell carcinoma (IMmotion151): a multicentre, open-label, phase 3, randomised controlled trial. Lancet. 2019 Jun 1. s.

46. Kapur P, Peña-Llopis S, Christie A, et al Effects on survival of BAP1 and PBRM1 mutations in sporadic clear-cell renal-cell carcinoma: a retrospective analysis with independent validation. Lancet Oncol. 2013 Feb;14(2):159-67.

47. Jorgensen TJ, Ruczinski I, Kessing B et al. Hypothesis-driven candidate gene association studies: practical design and analytical considerations. Am J Epidemiol. 2009 Oct 15;170(8):986-93.

48. Pareek CS, Smoczynski R, Tretyn A. Sequencing technologies and genome sequencing. J Appl Genet. 2011 Nov; 52(4): 413-435.

49. Prognostic or predictive plasma cytokines and angiogenic factors for patients treated with pazopanib for metastatic renal-cell cancer: a retrospective analysis of phase 2 and phase 3 trials. Lancet Oncol.

2012;13:827-837. . Tran HT, Liu Y, Zurita AJ et al.

50. Circulating biomarkers and outcome from a randomised phase II trial of sunitinib vs everolimus for patients with metastatic renal cell carcinoma. Br J Cancer. 2016;114:642-649. Voss MH, Chen D, Marker M, et al.

51. Circulating biomarkers for vascularendothelial growth factor inhibitors in renal cell carcinoma. Cancer 2009; 115:2346-2354. Zurita Aj, Jonasch E, Wu HK et al.

52. Distinct patterns of cytokine and angiogenic factor modulation and markers of benefit for vandetanib and/orchemotherapy in patients with non-small-cell lung cancer. J Clin Oncol 2010;28: 193-201.

53. H.T. Tran, Y. Liu, A.J. Zurita et al. Prognostic or predictive plasma cytokines and angiogenic factors for patients treated with pazopanib for metastatic renal-cell cancer: a retrospective analysis of phase 2 and phase 3 trials. Lancet Oncol, 13 (8) (2012), pp. 827-837. 
54. Prognostic or predictive plasma cytokines and angiogenic factors for patients treated with pazopanib for metastatic renal-cell cancer: a retrospective analysis of phase 2 and phase 3 trials.Lancet Oncol. 2012 Aug;13(8):827-37. . Tran HT1, Liu Y, Zurita AJ et al.

55. X Na, G Wu, CK Ryan, et al. Overproduction of vascular endothelial growth factor related to von HippelLindau tumor suppressor gene mutations and hypoxia-inducible factor-1 alpha expression in renal cell carcinomas J Urol 170: 588-592,2003.

56. Chemokine receptors. Cytokine Growth Factor Rev. 2001;12:313-335. doi: 10.1016/S13596101(01)00014-4. R., Horuk.

57. Chemokine receptor CXCR4 downregulated by von Hippel-Lindau tumour suppressor $p$ VHL. Nature. 2003;425:307-311. . Staller P, Sulitkova J, Lisztwan J et al.

58. Regulation of the chemokine receptor CXCR4 by hypoxia. J Exp Med. 2003;198:1391-1402. doi: 10.1084/jem.20030267. Schioppa T, Uranchimeg B, Saccani A et al.

59. Molecular subtypes of clear cell renal cell carcinoma are associated with sunitinib response in the metastatic setting. Clin Cancer Res 2015;21:1329-39. Beuselinck B, Job S, Becht E et al.

60. Prognostic or predictive plasma cytokines and angiogenic factors for patients treated with pazopanib for metastatic renal-cell cancer: a retrospective analysis of phase 2 and phase 3 trials. Lancet Oncol 2012;13:827-37. Tran HT, Liu Y, Zurita AJ, et al.

61. Zhao Z, Chen C, Lin J et al. Synergy between von Hippel-Lindau and P53 contributes to chemosensitivity of clear cell renal cell carcinoma. Mol Med Rep. 2016 Sep;14(3):2785-90. doi: 10.3892/mmr.2016.5561.

62. SK Pal, $\mathbf{G}$ Sonpavde, Agarwal $\mathbf{N}$ et al. Evolution of Circulating tumor DNA Profile from First-line to Subsequent Therapy in Metastatic Renal Cell Carcinoma. Eur Urol. 2017 Oct;72(4):557-564. doi: 10.1016/j.eururo.2017.03.046.

63. Escudier B, Eisen T, Stadler WM et al. Sorafenib for treatment of renal cell carcinoma: Final efficacy and safety results of the phase III treatment approaches in renal cancer global evaluation trial. J Clin Oncol. 2009 Jul 10;27(20):3312-8. doi: 10.1200/JCO.2008.19.5511.

64. John M. L. Ebos, Christina R. Lee, James G. Christensen et al. Multiple circulating proangiogenic factors induced by sunitinib malate are tumor-independent and correlate with antitumor efficacy. Proc Natl Acad Sci U S A. 2007 Oct 23;104(43):17069-74. Epub 2007 Oct 17.

\section{References}

1. Latif F, Tory K, Gnarra J, et al. Identification of the von Hippel-Lindau disease tumor suppressor gene. Science. 1993 May 28;260(5112):1317-20. 
2. Bukowski RM. Cytokine therapy for metastatic renal cell carcinoma. Semin Urol Oncol. 2001;19(2):148154.

3. Motzer RJ, Russo P. Systemic therapy for renal cell carcinoma. J Urol. 2000;163(2):408-417.

4. Rini BI, Small EJ. Biology and clinical development of vascular endothelial growth factor-targeted therapy in renal cell carci noma. J Clin Oncol. 2005;23(5):1028-1043.

5. Sonpavde G, Hutson TE, Sternberg CN. Pazopanib, a potent orally administered small-molecule multitargeted tyrosine kinase inhibitor for renal cell carcinoma. Expert Opin Investig Drugs. 2008 Feb;17(2):253-61.

6. Kumar R, Crouthamel MC, Rominger DH, et al. Myelosuppression and kinase selectivity of multikinase angiogenesis inhibitors. Br J Cancer. 2009 Nov 17;101(10):1717-23.

7. Sternberg CN, Davis ID, Mardiak J et al. Pazopanib in locally advanced or metastatic renal cell carcinoma: results of a randomized phase III trial. J Clin Oncol. 2010 Feb 20;28(6):1061-8.

8. Motzer RJ, Hutson TE, Cella D, et al. Pazopanib versus sunitinib in metastatic renal-cell carcinoma. N Engl J Med. 2013 Aug 22;369(8):722-31.

9. Schmidinger M, Bamias A, Procopio G et al. Prospective Observational Study of Pazopanib in Patients with Advanced Renal Cell Carcinoma (PRINCIPAL Study). Oncologist. 2019 Apr;24(4):491-497.

10. Procopio G, Bamias A, Schmidinger M et al. Real-world Effectiveness and Safety of Pazopanib in Patients With Intermediate Prognostic Risk Advanced Renal Cell Carcinoma. Genitourin Cancer. 2019 Jun;17(3):e526-e533.

11. Ravaud A, Gross-Goupil M. Overcoming resistance to tyrosine kinase inhibitors in renal cell carcinoma. Cancer Treat Rev. 2012 Dec;38(8):996-1003.

12. Hutson TE Targeted therapies for the treatment of metastatic renal cell carcinoma: clinical evidence. Oncologist. 2011;16 Suppl 2:14-22.

13. Hernandez-Yanez M, Heymach JV, Zurita AJ. Circulating biomarkers in advanced renal cell carcinoma: clinical applications. Curr Oncol Rep. 2012 Jun;14(3):221-9.

14. Bergers G, Hanahan D. Modes of resistance to anti-angiogenic therapy. Nat Rev Cancer 2008; 8(8):592603.

15. Shojaei F, Lee JH, Simmons BH et al. HGF/c-Met acts as an alternative angiogenic pathway in sunitinibresistant tumors. Cancer Res. 2010 Dec 15;70(24):10090-100.

16. Corso S, Giordano S. Cell-autonomous and non-cell-autonomous mechanisms of HGF/MET-driven resistance to targeted therapies: from basic research to a clinical perspective. Cancer Discov. 2013 Sep;3(9):978-92.

17. Zhang YW, Su Y, Volpert OV et al. Hepatocyte growth factor/scatter factor mediates angiogenesis through positive VEGF and negative thrombospondin 1 regulation. Proc Natl Acad Sci U S A. 2003 Oct 28;100(22):12718-23.

18. Waugh DJ, Wilson C. The interleukin-8 pathway in cancer. Clin Cancer Res. 2008 Nov 1;14(21):673541. 
19. Mizukami Y, Jo WS, Duerr EM et al. Induction of interleukin-8 preserves the angiogenic response in HIF-1alpha-deficient colon cancer cells. Nat Med. 2005 Sep;11(9):992-7.

20. Huang D, Ding $Y$, Zhou $M$ et al. Interleukin-8 mediates resistance to antiangiogenic agent sunitinib in renal cell carcinoma. Cancer Res. 2010 Feb 1;70(3):1063-71.

21. Tran HT, Liu Y, Zurita AJ et al. Prognostic or predictive plasma cytokines and angiogenic factors for patients treated with pazopanib for metastatic renal-cell cancer: a retrospective analysis of phase 2 and phase 3 trials. Lancet Oncol. 2012 Aug;13(8):827-37.

22. Ferrara N, Gerber HP, Lecouter J. The biology of VEGF and its receptors. Nat Med. 2003 Jun;9(6):66976.

23. Deprimo SE, Bello CL, Smeraglia J et al. Circulating protein biomarkers of pharmacodynamic activity of sunitinib in patients with metastatic renal cell carcinoma: modulation of VEGF and VEGF-related proteins. $\mathbf{J}$ Transl Med. 2007 Jul 2;5:32.

24. Zurita AJ, Jonasch $\mathrm{E}$, Wang $\mathrm{X}$ et al. A cytokine and angiogenic factor (CAF) analysis in plasma for selection of sorafenib therapy in patients with metastatic renal cell carcinoma. Ann Oncol, 23 (1) (2012), pp. 46-52.

25. SK Pal, G Sonpavde, Agarwal N et al. Evolution of Circulating tumor DNA Profile from First-line to Subsequent Therapy in Metastatic Renal Cell Carcinoma. Eur Urol. 2017 Oct;72(4):557-564.

26. Zhao Z, Chen C, Lin J et al. Synergy between von Hippel-Lindau and P53 contributes to chemosensitivity of clear cell renal cell carcinoma. Mol Med Rep. 2016 Sep;14(3):2785-90.

27. Negrier S, Perol D, Menetrier-Caux C, Escudier B et al. Interleukin-6, interleukin-10, and vascular endothelial growth factor in metastatic renal cell carcinoma: prognostic value of interleukin-6--from the Groupe Francais d'Immunoththerapie. J Clin Oncol. 2004;22(12):2371-8.

28. Montero AJ, Diaz-Montero CM, Millikan RE et al. Cytokines and angiogenic factors in patients with metastatic renal cell carcinoma treated with interferon-alpha: association of pretreatment serum levels with survival. Ann Oncol. 2009;20(10):1682-7.

29. Liu Y, Tran HT, Lin Y, Martin AM et al. Baseline (BL) IL-6, IL-8, and VEGF as Predictive and Prognostic Markers for Overall Survival (OS) in Metastatic Renal Cell Carcinoma (mRCC) Patients (pts) Treated in a Phase III Trial of Pazopanib (PAZO) Versus Placebo (PL). Eur J Cancer. 2011;47(suppl 1).

31. Harmon CS, DePrimo SE, Figlin RA et al. Circulating proteins as potential biomarkers of sunitinib and interferon-alpha efficacy in treatment-naive patients with metastatic renal cell carcinoma. Cancer Chemother Pharmacol 2014;73:151-61.

32. Terakawa T, Miyake H, Kusuda Y et al. Expression level of vascular endothelial growth factor receptor2 in radical nephrectomy specimens as a prognostic predictor in patients with metastatic renal cell carcinoma treated with sunitinib. Urol Oncol. 2013; 31:493-498.

33. DJ George, MD Michaelson, JE Rosenberg, et al. Phase II trial of sunitinib in bevacizumab-refractory metastatic renal cell carcinoma (mRCC): Updated results and analysis of circulating biomarkers J Clin Oncol 25: 243s,2007 suppl abstr 5035.

- Farace F, Gross-Goupil M, Tournay E et al. Levels of circulating CD45(dim)CD34(+)VEGFR2(+) progenitor cells correlate with outcome in metastatic renal cell carcinoma patients treated with 
tyrosine kinase inhibitors Br J Cancer. 2011 Mar 29;104(7):1144-50. doi: 10.1038/bjc.2011.72. Epub 2011 Mar 8;

- Kontovinis LF1, Papazisis KT, Touplikioti P, et al. Sunitinib treatment for patients with clear-cell metastatic renal cell carcinoma: clinical outcomes and plasma angiogenesis markers. BMC Cancer. 2009 Mar 12;9:82. doi: 10.1186/1471-2407-9-82.).

34. Horuk R. Chemokine receptors. Cytokine Growth Factor Rev. 2001;12:313-335.

35. Schioppa T, Uranchimeg B, Saccani A et al. Regulation of the chemokine receptor CXCR4 by hypoxia. J Exp Med. 2003;198:1391-1402.

36. Staller P, Sulitkova J, Lisztwan J et al. Chemokine receptor CXCR4 downregulated by von HippelLindau tumour suppressor pVHL. Nature. 2003;425:307-311.

37. Carmeliet P, Jain RK. Molecular mechanisms and clinical applications of angiogenesis. Nature 2011;473:298-307.

38. Beuselinck B, Job S, Becht E et al. Molecular subtypes of clear cell renal cell carcinoma are associated with sunitinib response in the metastatic setting. Clin Cancer Res 2015;21:1329-39.

39. John M. L. Ebos, Christina R. Lee, James G. Christensen et al. Multiple circulating proangiogenic factors induced by sunitinib malate are tumor-independent and correlate with antitumor efficacy. Proc Natl Acad Sci U S A. 2007 Oct 23;104(43):17069-74.

40. Kotteas EA, Boulas P, Gkiozos I et al. The intercellular cell adhesion molecule-1 (icam-1) in lung cancer: implications for disease progression and prognosis. Anticancer Res. 2014;34:4665-72.

41. Motzer RJ, Rini BI, McDermott DF et al. Nivolumab plus ipilimumab versus sunitinib in first-line treatment for advanced renal cell carcinoma: extended follow-up of efficacy and safety results from a randomised, controlled, phase 3 trial. Lancet Oncol. 2019 Oct;20(10):1370-1385.

42. Rini BI, Plimack ER, Stus V et al. Pembrolizumab plus Axitinib versus Sunitinib for Advanced RenalCell Carcinoma. March 21, 2019. N Engl J Med 2019; 380:1116-1127

43. Motzer RJ, Penkov K, Haanen J, et al. Avelumab plus Axitinib versus Sunitinib for Advanced Renal-Cell Carcinoma. March 21, 2019. N Engl J Med 2019; 380:1103-111

44. Rini BI, Powles T, Atkins MB, et al. Atezolizumab plus bevacizumab versus sunitinib in patients with previously untreated metastatic renal cell carcinoma (IMmotion151): a multicentre, open-label, phase 3, randomised controlled trial. Lancet. 2019 Jun 15;393(10189):2404-241.

\section{Figures.}




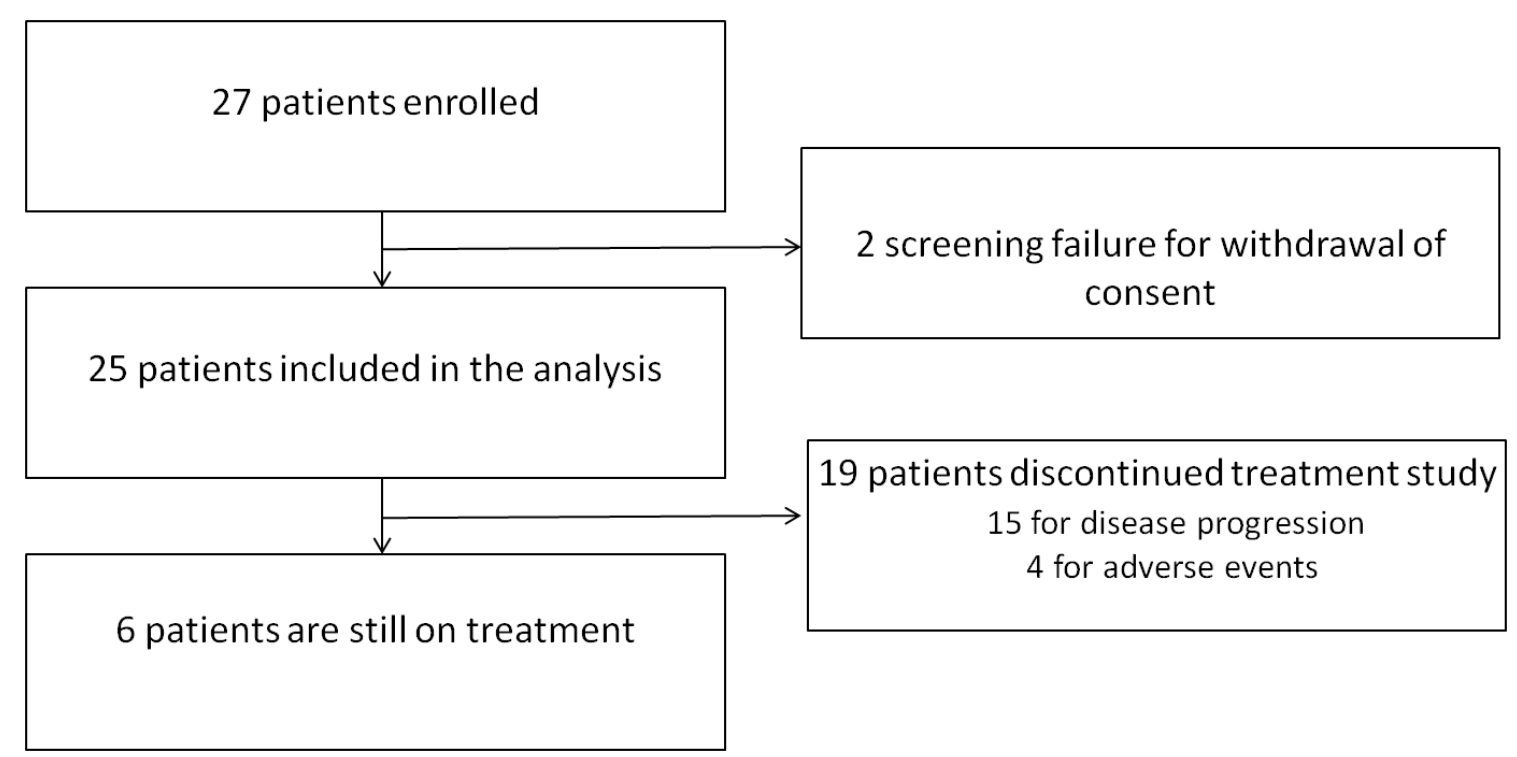

Fig 1. Treatment and follow up of the patients 
SDF1

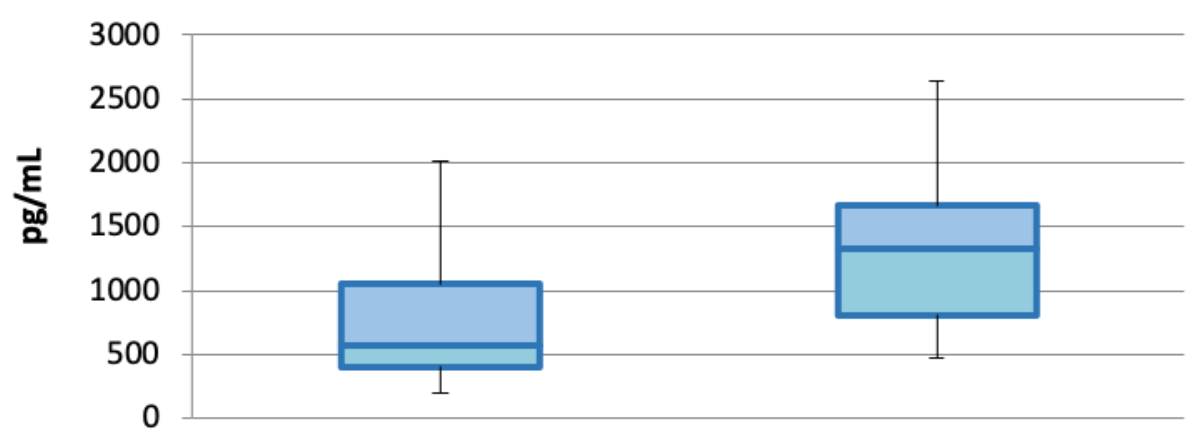

\section{VEGF}

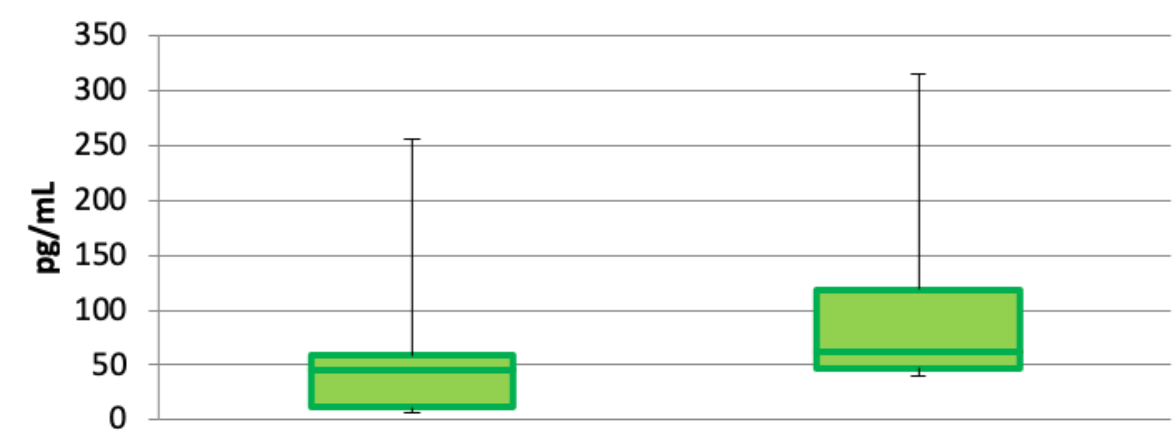

\section{E-Selectina}

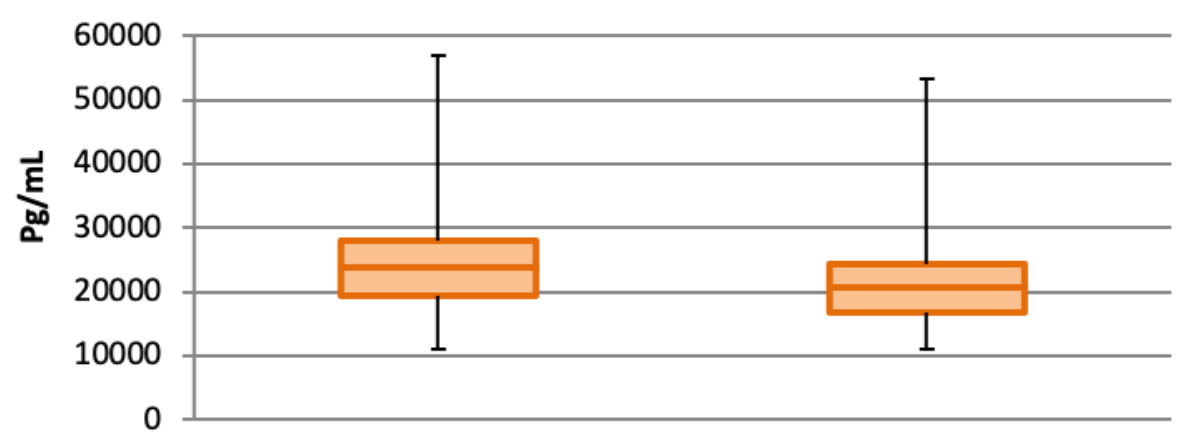

Fig 2. Significant changes in median CAF's plasma levels at PD compared to baseline during treatment with pazopanib 

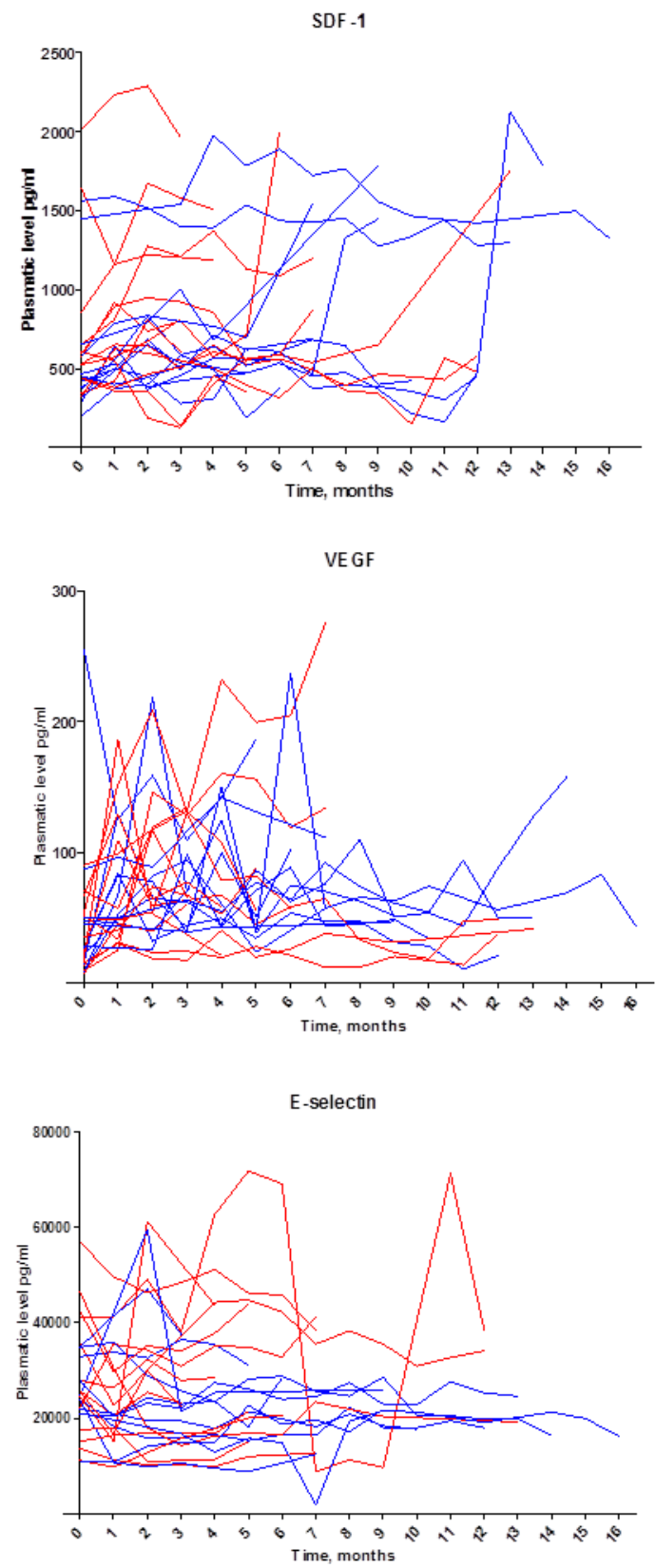

Fig 3. Change in CAF's level

In the Figure 3 the trend of the exact point values of CAFs (SDF-1, VEGF and E-selectin) at the different timepoints over time is graphically depicted. Blue lines: patients who achieved an objective response to treatment with pazopanib; Red lines: patients who did not achieve an objective response to treatment with pazopanib. 


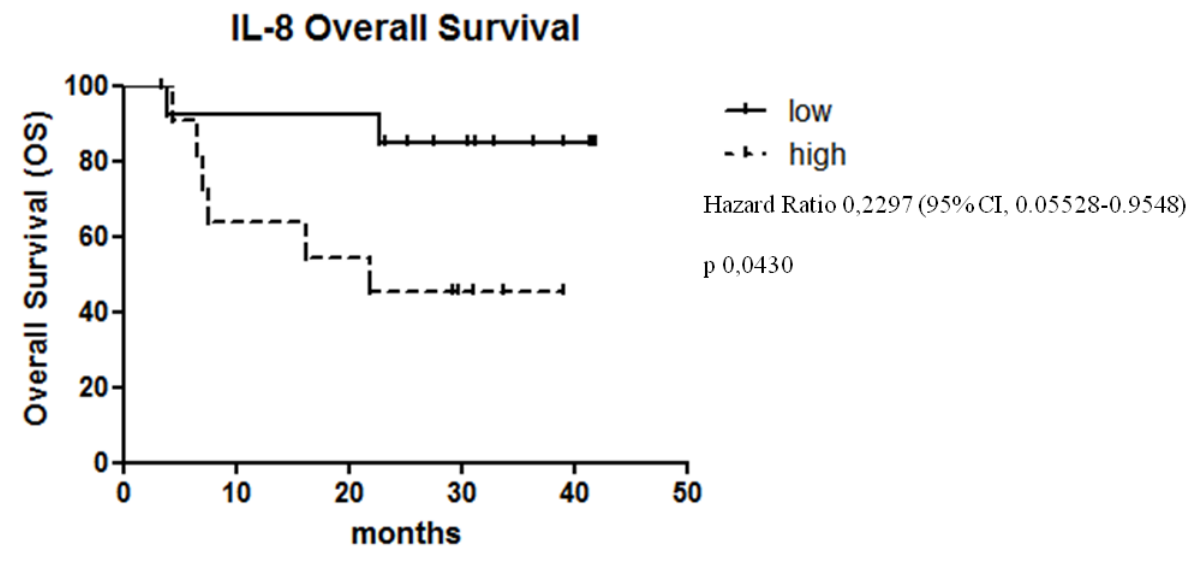

Fig 4. Kaplan-Meier Survival Curves of patients with low or high IL-8 levels at baseline

A

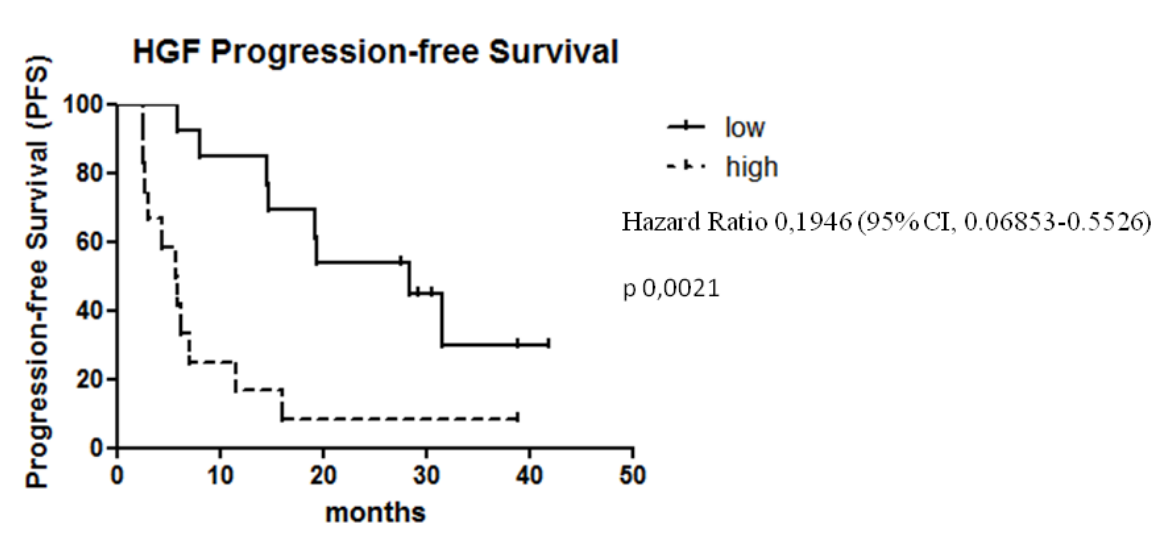

B HGF Overall Survival

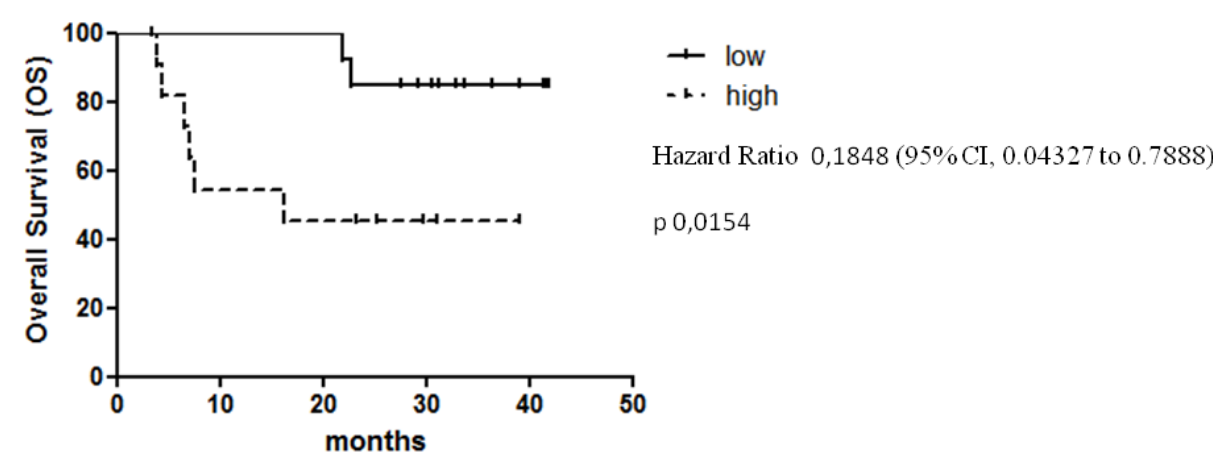

Fig 5. Progression-free survival (A) and overall survival (B) Kaplan-Meier Curves of patients with low or high HGF levels at baseline 

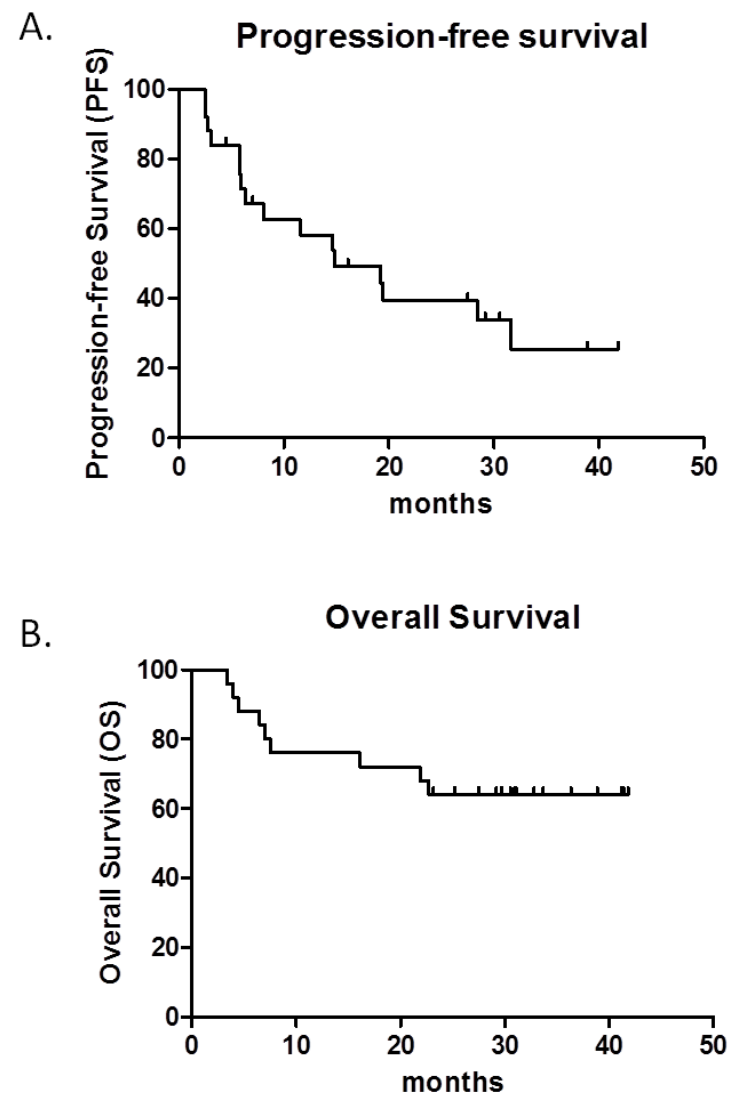

Suppl. Fig. 1. A) Progression free survival; B) Overall Survival 
A

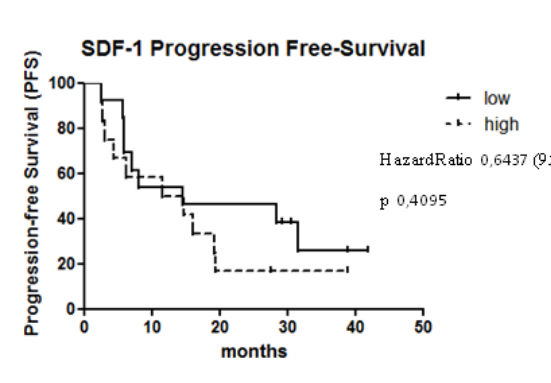

C

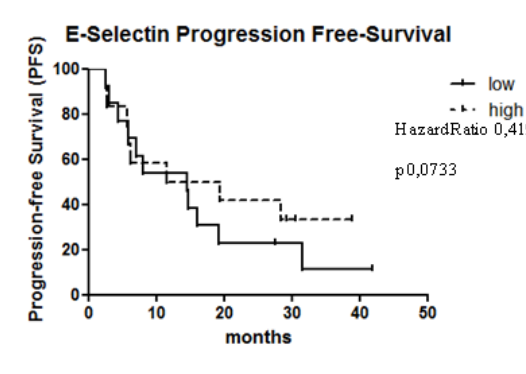

B

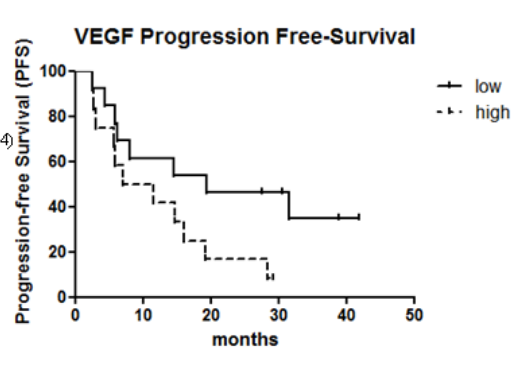

D

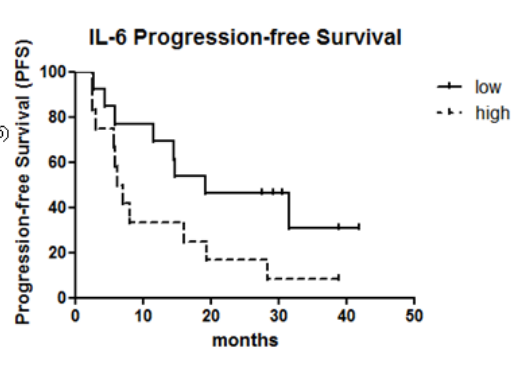

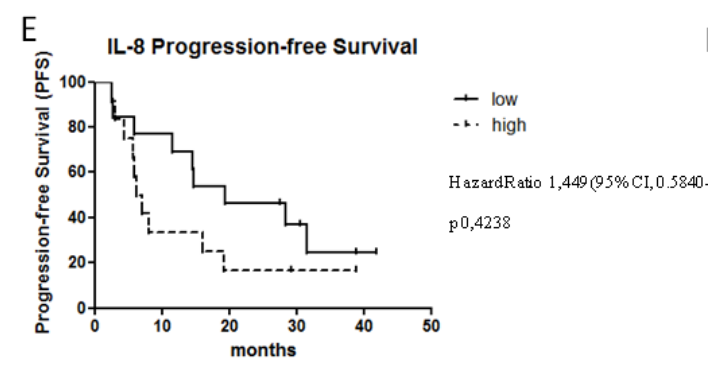

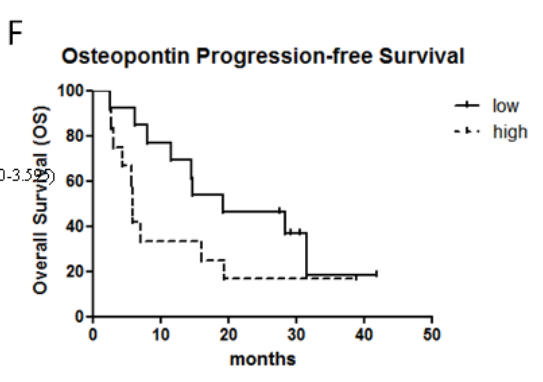

Suppl. Fig. 2 Progression-free survival Kaplan-Meier Curves of patients with low or high CAFs levels at baseline

(A) SDF-1. (B) IL-6. (C) VEGF. (D) IL-8. (E) E-selectin. (F) osteopontin. 

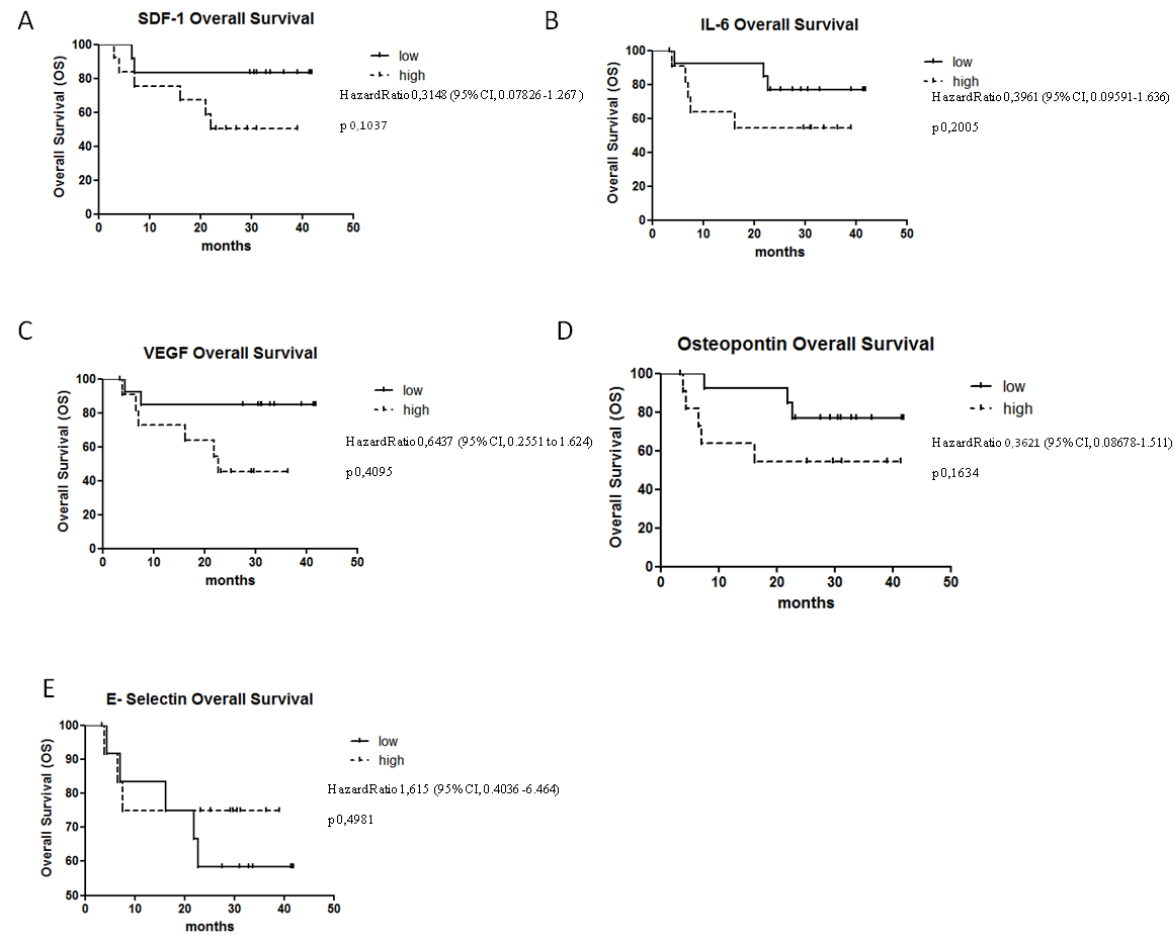

Suppl. Fig. 3 Kaplan-Meier Survival Curves of patients with low or high CAFs levels at baseline

(A) SDF-1. (B) IL-6. (C) VEGF. (D) Osteopontin (E) E-selectin. 
Tables.

\begin{tabular}{cc}
\hline Table 1. Baseline characteristics & \\
\hline Characteristic & No $(\%)$ \\
\hline Age, years & 65 \\
Median (Range) & $(54-73)$ \\
Sex & \\
Male & $21(84)$ \\
female & $4(16)$ \\
ECOG PS & $19(76)$ \\
0 & $6(24)$ \\
1 & \\
IMDC risk group & $8(32)$ \\
Good & $17(68)$ \\
Intermediate & \\
Prior Nephrectomy & $18(72)$ \\
Yes & $7(28)$ \\
No & \\
Site of metastases & $17(68)$ \\
Lung & $3(12)$ \\
Bone & $5(20)$ \\
Lymphnodes & $12(48)$ \\
Other & \\
\hline
\end{tabular}

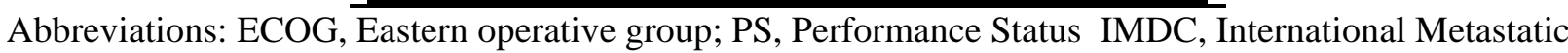
renal cell carcinoma database Consortium 


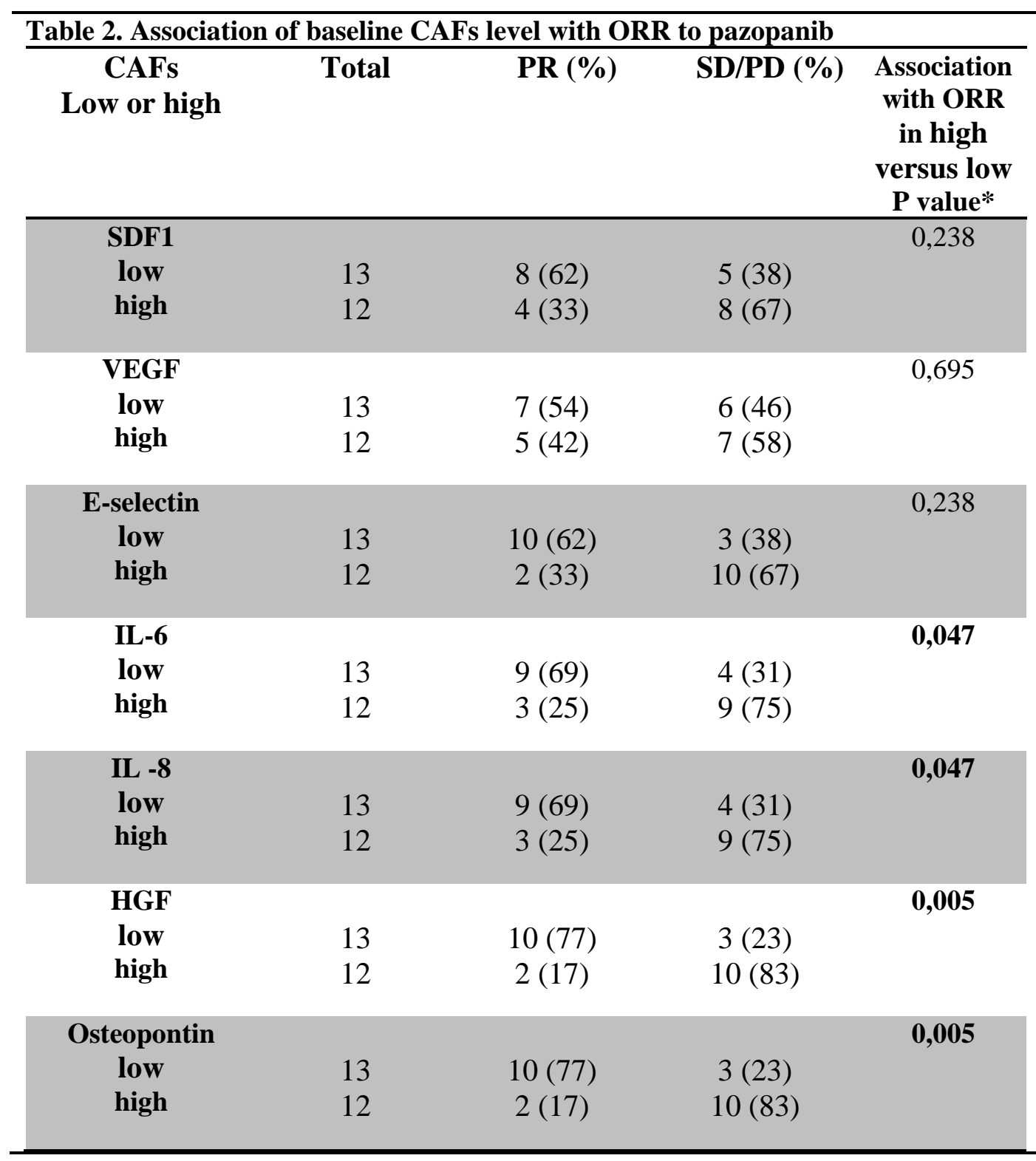

Abbreviations: CAF's, circulating angiogenic factors: ORR, objective response rate; PR, partial response; $\mathrm{SD}$, stable disease; $\mathrm{PD}$, progressive disease

*P value according to Fisher Exact Test 


\begin{tabular}{ccc}
\hline $\begin{array}{l}\text { Table 3. Association of baseline CAFs level with ORR to } \\
\text { pazopanib }\end{array}$ & $\begin{array}{c}\text { Cutoff value } \\
\text { (median } \\
\text { baseline value) }\end{array}$ & $\begin{array}{c}\text { Association with } \\
\text { ORR in high } \\
\text { versus low } \\
\text { P value* }\end{array}$ \\
\hline SDF1 (pg/mL) & 525,93 & 0,238 \\
VEGF-A (pg/mL) & 27,80 & 0,695 \\
\hline E-selectin (pg/mL) & $24.753,21$ & 0,238 \\
\hline IL-6 (pg/mL) & 5,69 & $\mathbf{0 , 0 4 7}$ \\
\hline IL -8 (pg/mL) & 8,89 & $\mathbf{0 , 0 4 7}$ \\
\hline HGF (pg/mL) & 71,62 & $\mathbf{0 , 0 0 5}$ \\
\hline $\begin{array}{l}\text { Osteopontin } \\
\text { (pg/mL) }\end{array}$ & $53.484,39$ & $\mathbf{0 , 0 0 5}$ \\
\hline
\end{tabular}

Abbreviations: CAFs, circulating angiogenic factors; ORR, objective response rate *P value according to Fisher Exact Test 


\begin{tabular}{|c|c|c|c|}
\hline CAFs & $\begin{array}{c}\text { Median baseline } \\
\text { value } \\
\text { (range) }\end{array}$ & $\begin{array}{c}\text { Median Value at PD } \\
\text { (range) }\end{array}$ & P value \\
\hline SDF1 (pg/mL) & $\begin{array}{c}574,67 \\
(200,8-2.018,39)\end{array}$ & $\begin{array}{c}1.328,03 \\
(472,55-2.126,96)\end{array}$ & $p=0,011$ \\
\hline VEGF (pg/mL) & $\begin{array}{c}45,10 \\
(6,16-256,14)\end{array}$ & $\begin{array}{c}62,4 \\
(39,42-186,74)\end{array}$ & $\mathbf{p}=\mathbf{0 , 0 1 1}$ \\
\hline E-selectin $(\mathrm{pg} / \mathrm{mL})$ & $\begin{array}{c}23.882,51 \\
(11.016,44-56.948,61)\end{array}$ & $\begin{array}{c}20.588,30 \\
(10.991,75-38.415,71)\end{array}$ & $p=0,017$ \\
\hline IL-6 (pg/mL) & $\begin{array}{c}5,84 \\
(0,63-261,34)\end{array}$ & $\begin{array}{c}11,85 \\
(0.10-70,33)\end{array}$ & $\mathrm{p}=0,57$ \\
\hline IL -8 (pg/mL) & $\begin{array}{c}8,38 \\
(1,52-38,769)\end{array}$ & $\begin{array}{c}5,99 \\
(0,89-25,89)\end{array}$ & $\mathrm{p}=0,61$ \\
\hline HGF (pg/mL) & $\begin{array}{c}76,13 \\
(27,85-259,65)\end{array}$ & $\begin{array}{c}99,09 \\
(39,8-241,89)\end{array}$ & $\mathrm{p}=0,39$ \\
\hline Osteopontin $(\mathrm{pg} / \mathrm{mL})$ & $\begin{array}{c}53.484,39 \\
(3.799,33-358.630,14)\end{array}$ & $\begin{array}{c}77.641,32 \\
(14.785,19-180.431,54)\end{array}$ & $\mathrm{p}=0,78$ \\
\hline
\end{tabular}

Abbreviations: $\mathrm{CAFs}$, circulating angiogenic factors; $\mathrm{PD}$, progressive disease

*P value according to Wilcoxon Test 